\title{
Respiratory physiology of COVID-19- induced respiratory failure compared to ARDS of other etiologies
}

Domenico Luca Grieco ${ }^{1,2^{*}}$ (D), Filippo Bongiovanni ${ }^{1,2}$, Lu Chen ${ }^{3,4}$, Luca S. Menga ${ }^{1,2}$, Salvatore Lucio Cutuli, ${ }^{1,2}$, Gabriele Pintaudi ${ }^{1,2}$, Simone Carelli, ${ }^{1,2}$, Teresa Michi ${ }^{1,2}$, Flava Torrini ${ }^{1,2}$, Gianmarco Lombardi ${ }^{1,2}$, Gian Marco Anzellotti ${ }^{1,2}$, Gennaro De Pascale ${ }^{1,2}$, Andrea Urbani, ${ }^{5,6}$, Maria Grazia Bocci ${ }^{1,2}$, Eloisa S. Tanzarella $a^{1,2}$, Giuseppe Bello ${ }^{1,2}$, Antonio M. Dell'Anna ${ }^{1,2}$, Salvatore M. Maggiore', Laurent Brochard ${ }^{3,4}$ and Massimo Antonelli, ${ }^{1,2}$

\begin{abstract}
Background: Whether respiratory physiology of COVID-19-induced respiratory failure is different from acute respiratory distress syndrome (ARDS) of other etiologies is unclear. We conducted a single-center study to describe respiratory mechanics and response to positive end-expiratory pressure (PEEP) in COVID-19 ARDS and to compare COVID-19 patients to matched-control subjects with ARDS from other causes.

Methods: Thirty consecutive COVID-19 patients admitted to an intensive care unit in Rome, Italy, and fulfilling moderate-to-severe ARDS criteria were enrolled within $24 \mathrm{~h}$ from endotracheal intubation. Gas exchange, respiratory mechanics, and ventilatory ratio were measured at PEEP of 15 and $5 \mathrm{cmH}_{2} \mathrm{O}$. A single-breath derecruitment maneuver was performed to assess recruitability. After 1:1 matching based on $\mathrm{PaO}_{2} / \mathrm{FiO}_{2}, \mathrm{FiO}_{2}, \mathrm{PEEP}$, and tidal volume, COVID-19 patients were compared to subjects affected by ARDS of other etiologies who underwent the same procedures in a previous study.

Results: Thirty COVID-19 patients were successfully matched with 30 ARDS from other etiologies. At low PEEP, median [25th-75th percentiles] $\mathrm{PaO}_{2} / \mathrm{FiO}_{2}$ in the two groups was $119 \mathrm{mmHg}$ [101-142] and $116 \mathrm{mmHg}$ [87-154]. Average compliance $\left(41 \mathrm{ml} / \mathrm{cmH}_{2} \mathrm{O}\right.$ [32-52] vs. $36 \mathrm{ml} / \mathrm{CmH}_{2} \mathrm{O}$ [27-42], $\left.p=0.045\right)$ and ventilatory ratio (2.1 [1.7-2.3] vs. 1.6 [1.4-2.1], $p=0.032$ ) were slightly higher in COVID-19 patients. Inter-individual variability (ratio of standard deviation to mean) of compliance was $36 \%$ in COVID-19 patients and 31\% in other ARDS. In COVID-19 patients, $\mathrm{PaO}_{2} / \mathrm{FiO}_{2}$ was linearly correlated with respiratory system compliance $(r=0.52 p=0.003)$. High PEEP improved $\mathrm{PaO}_{2} / \mathrm{FiO}_{2}$ in both cohorts, but more remarkably in COVID-19 patients $(p=0.005)$. Recruitability was not different between cohorts $(p=0.39)$ and was highly inter-individually variable (72\% in COVID-19 patients and 64\% in ARDS from other causes). In COVID-19 patients, recruitability was independent from oxygenation and respiratory mechanics changes due to PEEP.

(Continued on next page)
\end{abstract}

\footnotetext{
* Correspondence: dlgrieco@outlook.it

'Department of Emergency, Intensive Care Medicine and Anesthesia, Fondazione Policlinico Universitario A. Gemelli IRCCS, Rome, Italy

${ }^{2}$ Istituto di Anestesiologia e Rianimazione, Università Cattolica del Sacro Cuore, Rome, Italy

Full list of author information is available at the end of the article
}

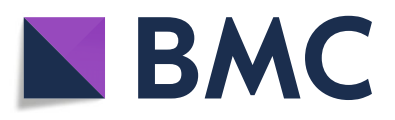

(c) The Author(s). 2020 Open Access This article is licensed under a Creative Commons Attribution 4.0 International License, which permits use, sharing, adaptation, distribution and reproduction in any medium or format, as long as you give appropriate credit to the original author(s) and the source, provide a link to the Creative Commons licence, and indicate if changes were made. The images or other third party material in this article are included in the article's Creative Commons licence, unless indicated otherwise in a credit line to the material. If material is not included in the article's Creative Commons licence and your intended use is not permitted by statutory regulation or exceeds the permitted use, you will need to obtain permission directly from the copyright holder. To view a copy of this licence, visit http://creativecommons.org/licenses/by/4.0/ The Creative Commons Public Domain Dedication waiver (http://creativecommons.org/publicdomain/zero/1.0/) applies to the data made available in this article, unless otherwise stated in a credit line to the data. 
(Continued from previous page)

Conclusions: Early after establishment of mechanical ventilation, COVID-19 patients follow ARDS physiology, with compliance reduction related to the degree of hypoxemia, and inter-individually variable respiratory mechanics and recruitability. Physiological differences between ARDS from COVID-19 and other causes appear small.

Keywords: COVID-19, ARDS, Respiratory mechanics, PEEP, Alveolar recruitment

\section{Background}

Around 5\% of patients affected by the novel 2019 coronavirus disease (COVID-19) require intensive care unit (ICU) admission due to acute respiratory distress syndrome (ARDS), with a case-fatality rate ranging between 30 and $60 \%$ [1-8]. Invasive mechanical ventilation is required in most of the patients to treat gas exchange abnormalities and represents the mainstay of supportive therapy $[4,7,9]$. In this setting, mechanical ventilation is aimed at restoring adequate gas exchange while limiting ventilator-induced lung injury (VILI) [10]. During ARDS, proper ventilatory management reduces the risk of VILI and is among the potentially modifiable factors capable of improving survival [11].

The effects of ventilator settings (tidal volume, positive end-expiratory pressure [PEEP]) on VILI and clinical outcome are mediated by respiratory mechanics that have wide inter-individual variability [12-14]. Thorough understanding of respiratory mechanics is essential to limit the risk of VILI and, possibly, improve clinical outcome $[15,16]$. Some reports suggested that patients with COVID-19 ARDS may have different phenotypes (high vs. low elastance), independently from gas exchange [17]. This could have important implications regarding ventilator management. Some authors claim that COVID-19 patients (or, at least, part of them) may not necessarily benefit from usual ARDS management [18]. However, whether or not the heterogeneity in respiratory mechanics observed in COVID-19 patients is different from conventional ARDS remains unclear [19-23].

We assessed respiratory mechanics, potential for lung recruitment, and PEEP effects in 30 consecutive mechanically ventilated patients with COVID-19-induced moderate-to-severe ARDS. After 1:1 matching based on the degree of oxygenation impairment at same PEEP and $\mathrm{FiO}_{2}$, we then compared these results with those obtained from a multicenter cohort of patients with ARDS of other origins who underwent the same procedures in a previous study.

\section{Methods}

This prospective study was conducted in the dedicated COVID-19 ICU of a tertiary care university hospital in Italy during March 2020. Approval was obtained by local institutional review board, and informed consent was obtained according to committee recommendations.

\section{Patients}

We screened all consecutive adult patients admitted to ICU between March 16 and 27, 2020, who were intubated due to acute hypoxemic respiratory failure with confirmed molecular diagnosis of COVID-19 (positive real-time polymerase chain reaction for viral RNA performed on an upper or lower respiratory tract specimen). Patients fulfilling criteria for moderate and severe ARDS according to the Berlin definition (i.e., $\mathrm{PaO}_{2} / \mathrm{FiO}_{2}$ ratio $\leq 200$, measured at $\mathrm{PEEP}=5 \mathrm{cmH}_{2} \mathrm{O}$ ) [24, 25] were enrolled within $24 \mathrm{~h}$ from endotracheal intubation.

Exclusion criteria were as follows: (1) age $<18$ years, (2) undrained pneumothorax, and (3) hemodynamic instability, defined as $>30 \%$ increase in vasopressor requirement during the previous $6 \mathrm{~h}$ or norepinephrine $>$ $0.5 \mu \mathrm{g} / \mathrm{kg} / \mathrm{min}$.

\section{Procedures and measurements}

For each patient, demographics, comorbidities, and 28day clinical outcome were recorded.

All measurements were conducted in the supine semirecumbent position within $24 \mathrm{~h}$ from endotracheal intubation, before any session of prone positioning. All patients were sedated and paralyzed with cisatracurium continuous infusion at a standard dose of $35 \mathrm{mg} / \mathrm{h} \mathrm{[26].}$ Mechanical ventilation was applied in the volumecontrolled mode with a heat and moisture exchanger, with the following settings: tidal volume $6 \mathrm{ml} / \mathrm{kg}$ of predicted body weight (PBW), inspiratory flow $60 \mathrm{l} / \mathrm{min}$, inspiratory pause $0.3 \mathrm{~s}$, respiratory rate titrated to obtain $\mathrm{pH}>7.30$ and $<35$ breaths per minute, and $\mathrm{FiO}_{2}$ titrated to achieve $\mathrm{SpO}_{2}$ between 90 and 96\%.

Two PEEP levels were tested in a sequential order: 15 (or the highest PEEP to obtain plateau pressure $\leq 28 \mathrm{cmH}_{2} \mathrm{O}$ ) and $5 \mathrm{cmH}_{2} \mathrm{O}$. After $30 \mathrm{~min}$ of ventilation with $\mathrm{PEEP}=15$ $\mathrm{cmH}_{2} \mathrm{O}$, arterial blood gasses and hemodynamics were recorded. Inspiratory $(1.5 \mathrm{~s})$ and expiratory $(4 \mathrm{~s})$ holds were performed, and the following parameters collected:

- Respiratory mechanics: Peak airway pressure, plateau pressure, and total PEEP were measured. Driving pressure, respiratory system compliance, and its PBW-indexed value were computed. Ventilatory ratio, which is an estimate of dead space fraction, was calculated (tidal volume $\times$ respiratory rate $\times \mathrm{PaCO}_{2}$ )/ $(\mathrm{PBW} \times 100 \times 37.5)[27]$. 
- Recruitability: A single-breath derecruitment maneuver was performed by decreasing PEEP by 10 $\mathrm{cmH}_{2} \mathrm{O}[28,29]$; exhaled tidal volume after PEEP lowering was recorded, and recruitment-to-inflation ratio was computed [29] — patients with recruitment-to-inflation ratio $\geq 0.5$ were considered having high recruitability.

Afterwards, ventilation was resumed with previous settings and PEEP $=5 \mathrm{cmH} 2 \mathrm{O}$. After $30 \mathrm{~min}$, blood gasses, hemodynamics, and respiratory mechanics were reassessed as described. Lastly, low-flow $(5 \mathrm{l} / \mathrm{min})$ inflation was performed after prolonged exhalation to assess airway closure, and airway opening pressure was recorded if present [30-33].

\section{Comparison with non-COVID-19 ARDS}

COVID-19 patients were compared to a cohort of subjects with moderate-to-severe ARDS from other etiologies who underwent exactly the same procedures in a previous study [29]. Two investigators (DLG and LC) were directly involved in patients' enrolment in both studies. This ensures reproducibility of the measurements and consistency in ventilator settings and circuit setup. COVID-19 patients were matched in 1:1 ratio to patients from the non-COVID-19 ARDS cohort. Matching was based on $\mathrm{PaO}_{2} / \mathrm{FiO}_{2}( \pm 20 \mathrm{mmHg}), \mathrm{FiO}_{2}( \pm 0.2)$, PEEP $\left( \pm 3 \mathrm{cmH}_{2} \mathrm{O}\right)$, and tidal volume $( \pm 1.5 \mathrm{ml} / \mathrm{kg}$ of predicted body weight). For matching, priority was given to $\mathrm{PaO}_{2} / \mathrm{FiO}_{2}$ (100\% adherence to the criterion), followed by $\mathrm{FiO}_{2}$ ( $93 \%$ adherence to the criterion, for "2 matches" criterion increased to \pm 0.4 ), tidal volume (93\% adherence to the criterion, for " 2 matches" criterion increased to $\pm 2.5 \mathrm{ml} / \mathrm{kg}$ ), and PEEP ( $90 \%$ adherence to the criterion, for "3 matches" criterion increased to $\pm 5 \mathrm{cmH}_{2} \mathrm{O}$ ). Individual data of matched subjects are provided in supplementary table 1 .

\section{Endpoints}

The aims of the study were to describe respiratory mechanics, potential for lung recruitment, and response to PEEP in COVID-19-induced ARDS patients and to compare these features to those of patients affected by ARDS of other causes.

\section{Sample size and statistical analysis}

At the time of study design, systematic data on respiratory mechanics in COVID-19 patients were lacking. Hence, a convenience sample of 30 consecutive patients was chosen to provide a timely report. Categorical data are reported as number of events (\%), and continuous data are displayed as medians [interquartile range]. Comparisons of continuous variables at the two PEEP levels were performed with the $T$ test for paired samples: mean differences [95\% confidence intervals, CI95\%] are displayed for most significant results. Categorical variables were compared with the McNemar test. Interindividual variability was calculated as the ratio of standard deviation to mean of the measurements.

Comparisons of continuous variables between COVID-19 and ARDS cohort were performed with the $T$ test for independent samples: mean differences are displayed for significant results. Categorical variables were compared with the chi-square or Fisher exact test, as appropriate.

Correlations were assessed with Pearson's correlation: $r$ and $p$ are provided for each comparison. Results with two-tailed $p \leq 0.05$ were considered statistically significant. Statistical analysis was performed with SPSS 20.0 (IBM Corporation, Armonk, NY, USA). Manuscript figures were prepared with GraphPad Prism (La Jolla, CA, USA).

\section{Results \\ COVID-19 cohort}

Thirty patients were enrolled. Demographics and relevant clinical characteristics are reported in Table 1. Twenty-three (77\%) patients met the criteria for moderate ARDS, and 7 (23\%) for severe ARDS.

\section{Matched cohorts}

Thirty patients from the historical ARDS cohort were successfully matched to COVID-19 patients (individual data provided in supplementary Table 1 , demographics in Table 1). At low PEEP, median $\mathrm{PaO}_{2} / \mathrm{FiO}_{2}$ was 119 $\mathrm{mmHg}$ [101-142] in COVID-19 patients and $116 \mathrm{mmHg}$ [87-154] in patients with ARDS from other etiologies. $\mathrm{FiO}_{2}$ was not different between cohorts $(p=0.51)$, while tidal volume was slightly higher, and PEEP lower, in patients with COVID-19 than controls. Although statistically significant, mean differences between cohorts were clinically negligible: $0.3 \mathrm{ml} / \mathrm{kg}$ [CI95\% $0-0.6]$ and 0.9 $\mathrm{cmH}_{2} \mathrm{O}$ [CI95\% 0.1-1.7], respectively. All COVID-19 patients were studied within $24 \mathrm{~h}$ from endotracheal intubation. Patients in the historical cohort underwent study procedures after a median time from ICU admission of 5 [3-10] days.

\section{Respiratory mechanics}

These results are displayed in Fig. 1 and Table 2.

Airway closure in COVID-19 cohort was less frequent than in ARDS from other etiologies: 2 (7\%) vs. 10 (30\%) patients $(p=0.021)$. At low PEEP, inter-individual variability of respiratory system compliance was $36 \%$ in COVID-19 patients and $31 \%$ in ARDS from other causes. Average respiratory system compliance and respiratory system compliance/PBW were slightly higher in patients with COVID-19 than in those affected by 
Table 1 Demographics and baseline characteristics of enrolled patients

\begin{tabular}{|c|c|c|}
\hline & COVID-19 cohort, $n=30$ & Non-COVID-19 cohort, $n=30$ \\
\hline Age, years & 70 [63-77] & $61[51-69]$ \\
\hline Female sex, no. (\%) & $7(23)$ & $4(13)$ \\
\hline Height, cm & $170[170-175]$ & $171[167-180]$ \\
\hline Predicted body weight, kg & $66[62-75]$ & 66 [59-75] \\
\hline Body mass index, $\mathrm{kg} / \mathrm{m}^{2}$ & 28 [25-29] & $33[27-40]$ \\
\hline SOFA at study inclusion & $8[7-10]$ & 14 [10-15] \\
\hline SAPS $\|$ & $45[34-58]$ & \\
\hline \multicolumn{3}{|l|}{ Comorbidities, no. (\%) } \\
\hline Hypertension & $19(63)$ & \\
\hline Active cancer & $3(10)$ & \\
\hline Chronic obstructive pulmonary disease & $3(10)$ & \\
\hline Diabetes mellitus & $2(7)$ & \\
\hline Coronary artery disease & $1(3)$ & \\
\hline Other & $10(33)$ & \\
\hline \multicolumn{3}{|l|}{ ARDS risk factors, no. (\%) } \\
\hline Pneumonia & $30(100)$ & $10(33)$ \\
\hline Aspiration & $0(0)$ & $4(13)$ \\
\hline Extrapulmonary sepsis & $0(0)$ & $4(13)$ \\
\hline Trauma & $0(0)$ & $2(7)$ \\
\hline Other & $0(0)$ & $10(33)$ \\
\hline Noninvasive respiratory support before intubation, no. (\%) & $20(67)$ & \\
\hline Duration of noninvasive respiratory support before intubation, hours & 19 [9-63] & \\
\hline \multicolumn{3}{|l|}{ ARDS severity at enrollment, no. (\%) } \\
\hline Moderate $\left(\mathrm{PaO}_{2} / \mathrm{FiO}_{2}\right.$ ratio $\left.101-200 \mathrm{mmHg}\right)$ & $23(77)$ & $22(73)$ \\
\hline Severe $\left(\mathrm{PaO}_{2} / \mathrm{FiO}_{2}\right.$ ratio $\left.\leq 100 \mathrm{mmHg}\right)$ & $7(23)$ & $8(27)$ \\
\hline Prone positioning during the ICU stay, no. (\%) & $21(70)$ & \\
\hline Acute kidney failure, no. (\%) & $15(50)$ & \\
\hline ICU-acquired infection, no. (\%) & $9(30)$ & \\
\hline Pneumothorax, no. (\%) & $4(13)$ & \\
\hline Tracheostomy, no. (\%) & $8(27)$ & \\
\hline \multicolumn{3}{|l|}{ 28-day outcome, no. (\%) } \\
\hline Dead & $19(63)$ & $9(30)$ \\
\hline Alive, receiving mechanical ventilation & $3(10)$ & \\
\hline Alive, breathing unassisted & $8(27)$ & \\
\hline
\end{tabular}

Data expressed in median [interquartile range], if not otherwise specified

other ARDS: mean differences were $7 \mathrm{ml} / \mathrm{cmH}_{2} \mathrm{O}$ [C195\% 0-14] and $0.11 \mathrm{ml} / \mathrm{cmH}_{2} \mathrm{O} / \mathrm{kg}$ [CI95\% $0.2-$ $0.20]$, respectively. This was not associated to statistically significant differences in the driving pressure $(p=0.098)$. In both cohorts, twenty-four (80\%) patients showed driving pressure equal or lower than $14 \mathrm{cmH}_{2} \mathrm{O}$. In the COVID-19 cohort, respiratory system compliance $(r=0.52, p=0.003)$ and respiratory system compliance/PBW $(r=0.53, p=0.002)$ were linearly related to $\mathrm{PaO}_{2} / \mathrm{FiO}_{2}$ (Fig. 2).
In COVID-19 cohort, ventilatory ratio was higher than in ARDS from other etiologies (mean difference 0.3 [CI95\% 0-0.6], $p=0.032$ ). In COVID-19 cohort, ventilatory ratio was not related to $\mathrm{PaO}_{2} / \mathrm{FiO}_{2}(p=0.42)$ nor to respiratory system compliance $(p=0.46)$.

\section{Response to PEEP — gas exchange and respiratory mechanics}

These results are displayed in Table 2 and Figs. 3 and 4. 

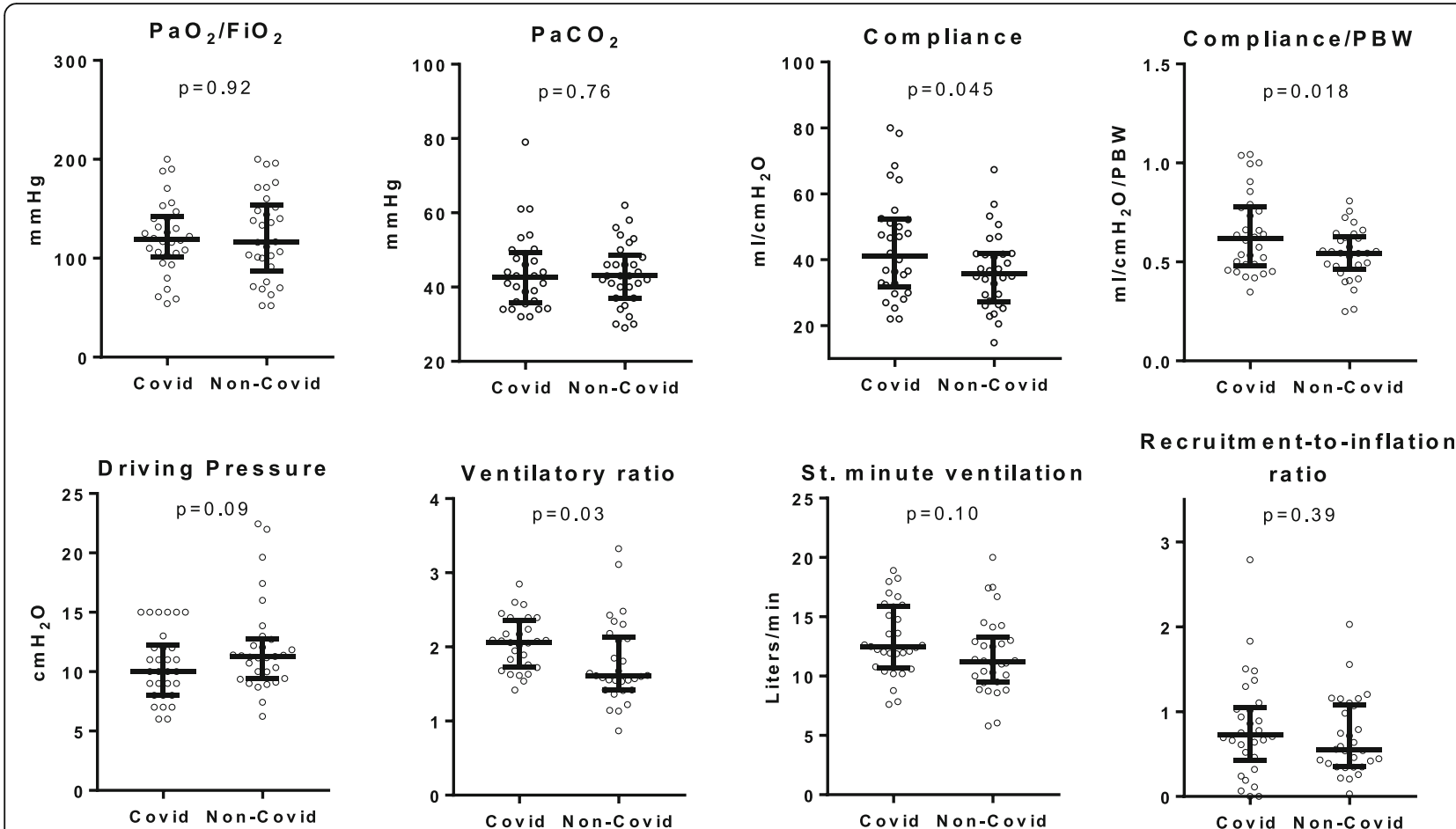

Fig. 1 Respiratory mechanics. Individual values, medians, and interquartile range showing the distribution of respiratory variables in the matched cohorts. For each variable, COVID-19 patients' values are compared to those for matched non-COVID-19 ARDS patients, as detailed in text. PaO $/$ $\mathrm{FiO}_{2}$ ratio, $\mathrm{PaCO}_{2}$, respiratory system compliance, driving pressure, ventilatory ratio, and standardized minute ventilation were measured at low PEEP. Ventilatory ratio, compliance, and its predicted body weight-indexed value were slightly higher in COVID-19 patients than in ARDS of other etiologies. PBW, predicted body weight

High PEEP yielded improvement in $\mathrm{PaO}_{2} / \mathrm{FiO}_{2}$ in both cohorts. The PEEP-induced improvement in $\mathrm{PaO}_{2} / \mathrm{FiO} 2$ was greater in COVID-19 patients than among subjects with non-COVID-19 ARDS: median PEEP-induced changes in $\mathrm{PaO}_{2} / \mathrm{FiO}_{2}$ were $42 \mathrm{mmHg}$ [24-62] vs. 27 $\mathrm{mmHg}$ [5-42], respectively $(p=0.005)$. In $27(97 \%)$ patients of COVID-19 cohort, high PEEP yielded improvement in $\mathrm{PaO}_{2} / \mathrm{FiO}_{2}$.

In both cohorts, PEEP did not affect $\mathrm{PaCO}_{2}$ nor ventilatory ratio. In COVID-19 patients, respiratory system compliance and driving pressure did not change with high PEEP: in ARDS from non-COVID-19 etiology, high PEEP reduced compliance by $5 \mathrm{ml} / \mathrm{cmH}_{2} \mathrm{O}$ [CI95\% 2-8] and increased driving pressure by $2 \mathrm{cmH}_{2} \mathrm{O}$ [CI95\% 1-3].

In both cohorts, high PEEP caused reduction in systolic arterial pressure, without affecting heart rate and diastolic pressure.

\section{Response to PEEP_recruitability}

Median recruitment-to-inflation ratio (i.e., recruitability) was 0.73 [0.43-1.04] in COVID-19 patients and 0.55 [0.35-1.08] in ARDS from other causes $(p=0.39)$. Interindividual variability of the recruitment-to-inflation ratio was $72 \%$ and $64 \%$, respectively. Recruitment-to-inflation ratio was greater than 0.5 in 22 COVID-19 patients
(73\%) vs. 17 patients (57\%) from the non-COVID-19 ARDS cohort $(p=0.28)$.

In COVID-19 patients, recruitment-to-inflation ratio had a weak but significant inverse correlation with respiratory system compliance recorded at low PEEP $(r=$ -0.37, $p=0.04)$. Recruitment-to-inflation ratio had no relationship with the change in $\mathrm{PaO}_{2} / \mathrm{FiO}$ caused by high PEEP $(p=0.45)$ but had a reverse linear relationship with the change in $\mathrm{PaCO}_{2}$ due to PEEP $(r=-0.46 p=$ 0.010) (Fig. 4).

Recruitment-to-inflation was not different between patients who showed increased, decreased, or unchanged respiratory system compliance (and driving pressure) with high PEEP $(p=0.14)$.

\section{Clinical outcome}

At 28 days, 19 (63\%) patients in the COVID-19 cohort had died and $3(10 \%)$ were still on mechanical ventilation.

\section{Discussion}

The result of this matched-cohort study can be summarized as follows: 
Table 2 Respiratory mechanics

\begin{tabular}{|c|c|c|c|c|c|c|}
\hline & \multicolumn{3}{|l|}{ LOW PEEP } & \multicolumn{3}{|l|}{ High PEEP } \\
\hline & COVID-19 & Non-COVID-19 & $p$ & COVID-19 & Non-COVID-19 & $p$ \\
\hline Set PEEP, $\mathrm{cmH}_{2} \mathrm{O}$ & $5[5-5]^{*}$ & $5[5-8]^{\S}$ & 0.031 & $15[15-15]^{*}$ & $15[15-18]^{\S}$ & 0.011 \\
\hline Total PEEP, $\mathrm{cmH}_{2} \mathrm{O}$ & $5[5-6]^{*}$ & $8[6-9]^{5}$ & $<0.001$ & $15[15-16]^{*}$ & $16[15-18]^{\S}$ & 0.001 \\
\hline Tidal volume, ml & 431 [395-473] & 414 [370-443] & 0.15 & 431 [395-473] & 417 [357-445] & 0.20 \\
\hline Tidal volume/PBW, ml/kg & $6.4[6-6.8]$ & $6[5.7-6.3]$ & 0.037 & $6.4[6-6.8]$ & $6[5.8-6.3]$ & 0.036 \\
\hline Respiratory rate, breaths/minute & 28 [26-30] & $26[24-30]$ & 0.16 & $28[26-30]$ & 26 [24-30] & 0.11 \\
\hline $\mathrm{PaO}_{2} / \mathrm{FiO}_{2}, \mathrm{mmHg}$ & $119[101-142]^{*}$ & $116[87-154]^{\S}$ & 0.92 & $165[132-196]^{*}$ & $150[121-192]^{\S}$ & 0.049 \\
\hline $\mathrm{pH}$ & $7.35[7.29-7.42]$ & $7.37[7.33-7.40]$ & 0.63 & $7.35[7.32-7.42]$ & $7.36[7.32-7.40]$ & 0.45 \\
\hline $\mathrm{PaCO}_{2}, \mathrm{mmHg}$ & 43 [37-49] & $43[37-49]$ & 0.76 & $43[36-49]$ & 45 [35-49] & 0.91 \\
\hline Ventilatory ratio & $2.1[1.7-2.3]$ & $1.6[1.4-2.1]$ & 0.032 & $2.1[1.7-2.4]$ & $1.7[1.4-2.2]$ & 0.08 \\
\hline Standardized minute ventilation, liters/minute & $12.4[10.7-15.6]$ & $11.1[9.5-13.3]$ & 0.12 & $12.4[10.7-15.9]$ & $11.5[9.7-14.2]$ & 0.29 \\
\hline Peak pressure, $\mathrm{CmH}_{2} \mathrm{O}$ & $29[23-32]^{*}$ & $33[29-39]^{\S}$ & 0.003 & $39[36-41]^{*}$ & $41[39-46]^{\S}$ & 0.043 \\
\hline Plateau pressure, $\mathrm{cmH}_{2} \mathrm{O}$ & $15[14-17]^{*}$ & $19[16-22]^{\S}$ & $<0.001$ & $26[25-29]^{*}$ & $30[28-33]^{\S}$ & $<0.001$ \\
\hline Inspiratory resistance, $\mathrm{cmH}_{2} \mathrm{O} /$ liters/second & $12[10-14]$ & $14[11-16]^{\S}$ & 0.09 & $12[10-14]$ & $12[10-14]^{\S}$ & 0.55 \\
\hline Driving pressure, $\mathrm{CmH}_{2} \mathrm{O}$ & $10[8-12]$ & $11[9-13]^{\S}$ & 0.09 & $10[9-14]$ & $13[11-17]^{\S}$ & 0.007 \\
\hline Patients with driving pressure $\leq 14 \mathrm{cmH}_{2} \mathrm{O}$, no. (\%) & $24(80)$ & $25(83)$ & 1 & $24(80)$ & $21(70)$ & 0.55 \\
\hline Respiratory system compliance, $\mathrm{ml} / \mathrm{cmH}_{2} \mathrm{O}$ & $41[32-52]$ & $36[27-42]^{\S}$ & 0.045 & $39[27-53]$ & $32[23-40]^{\S}$ & 0.003 \\
\hline Respiratory system compliance/PBW, $\mathrm{ml} / \mathrm{cmH}_{2} \mathrm{O} / \mathrm{kg}$ & $0.62[0.48-0.78]$ & $0.54[0.46-0.63]^{\S}$ & 0.018 & $0.57[0.45-0.75]$ & $0.47[0.37-0.56]^{\S}$ & $<0.001$ \\
\hline \multicolumn{7}{|l|}{ Arterial pressure, $\mathrm{mmHg}$} \\
\hline Systolic & $130[112-140]^{*}$ & $124[110-131]^{\S}$ & 0.27 & $118[110-126]^{*}$ & $116[104-126]^{\S}$ & 0.71 \\
\hline Diastolic & $70[57-80]$ & $60[55-64]$ & 0.017 & $65[54-70]$ & $57[54-62]$ & 0.08 \\
\hline Heart rate, beats per minute & 78 [70-93] & 82 [74-101] & 0.15 & 80 [70-92] & 85 [75-103] & 0.15 \\
\hline
\end{tabular}

Data are expressed as medians [interquartile range], if not otherwise specified

${ }^{*} p<0.05$ for the comparison between low and high PEEP within the COVID-19 cohort

${ }^{5} p<0.05$ for the comparison between low and high PEEP within the non-COVID-19 cohort

- In COVID-19 patients, the severity of hypoxemia was related to respiratory system compliance reduction. This suggests that aeration loss is a relevant mechanism of hypoxemia.

- Similarly to ARDS from other causes, respiratory mechanics of COVID-19 patients was highly heterogeneous.

- Average respiratory system compliance and ventilatory ratio of COVID-19 patients were slightly higher than those of ARDS from other etiologies. Although statistically significant, differences appear clinically small.

- The potential for PEEP-induced lung recruitment was variable. Average recruitability was similar to ARDS from non-COVID etiology. COVID-19 patients showed frank oxygenation response to PEEP, independently from recruitability.

\section{Respiratory mechanics}

Few data are available about respiratory mechanics and response to PEEP COVID-19 patients with acute respiratory failure [18-20, 34]. Our study compared respiratory mechanics and response to PEEP of patients with COVID-19 with those of matched ARDS from other etiologies, who have undergone the same procedures.

In our study, respiratory mechanics was highly heterogenous both in COVID-19 patients and in ARDS of other etiologies. Average values of respiratory system compliance were slightly higher in COVID-19 patients. Albeit statistically significant, mean difference $(7 \mathrm{ml} /$ $\mathrm{cmH}_{2} \mathrm{O}$ ) may not be clinically relevant. This may depend on the small differences in body mass index between the two cohorts, and heterogeneous ARDS causes in the control group. In COVID-19 patients, compliance reduction was linearly related to oxygenation impairment: this indicates that aeration loss is a causative mechanism of hypoxemia, which is the hallmark of ARDS pathophysiology (i.e., the baby lung) [35-38].

Gattinoni et al. have hypothesized that the acute respiratory failure caused by COVID-19 is a time-related disease spectrum within different phenotypes [18]. Our results indicate that, soon after intubation, heterogeneity and average values of respiratory mechanics are similar to ARDS of other etiologies. Our data come from a limited sample. However, results appear consistent with 


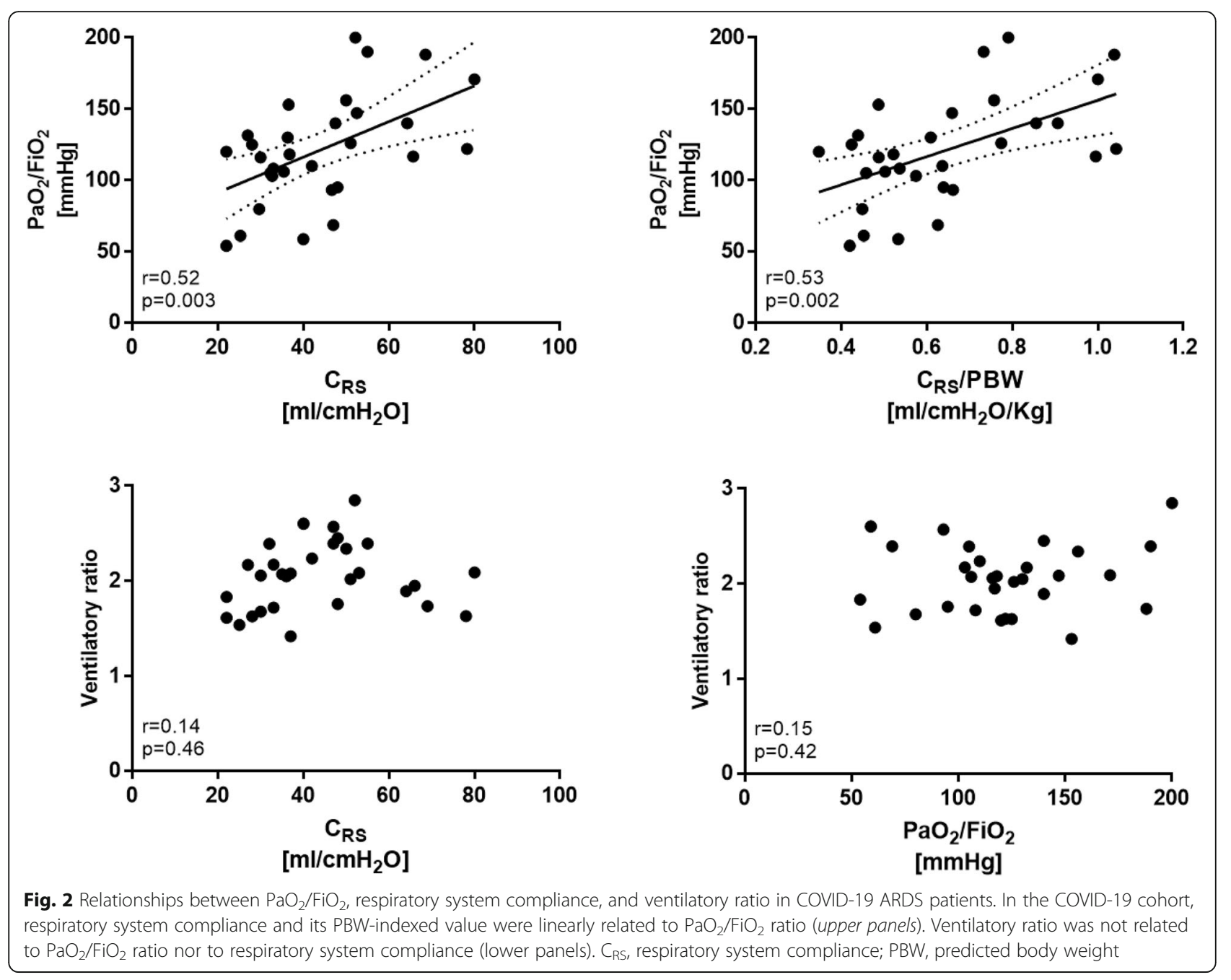

those of a recent large study on 742 patients [39] and with the recently published physiologic data by Haudebourg and coworkers [19]. They found no major differences in respiratory mechanics between patients with ARDS from COVID-19 and other etiologies. They did not exactly match their patients as done in our study, but could not detect relevant differences between ARDS from COVID-19 and other etiologies. Also, other authors have reported high heterogeneity in the respiratory mechanics and response to PEEP of COVID-19 patients $[22,40,41]$. These considerations strengthen the hypothesis that, from a ventilatory standpoint, clinicians should approach COVID-19 patients who fulfill ARDS criteria with our current evidence-based practices, informed by bedside physiology [15, 42-44].

Whether the microvascular involvement represents a disease-specific feature of COVID-19 disease is debated $[27,45]$. In our study, ventilatory ratio was slightly higher in COVID-19 patients than in ARDS of other causes. The ventilatory ratio is correlated with dead space and can reflect microvascular thrombosis, which yields ventilation-perfusion mismatch [22]. However, microcirculatory involvement and increased dead space are hallmarks of ARDS as well [46, 47]. Larger cohorts will be needed to subtle differences on this specific aspect.

\section{Response to PEEP—gas exchange}

More than $95 \%$ of patients improved oxygenation with high PEEP, independently from recruitability. The oxygenation improvement achieved with high PEEP was greater in COVID-19 patients than in patients affected by ARDS of other causes, although the potential for lung recruitment was not different. PEEP-induced improvement in oxygenation without alveolar recruitment could be caused by decreased cardiac output, with redistribution of lung perfusion towards the normally aerated compartment [22, 34]. This indicates that, similarly to ARDS from other causes, the oxygenation response to PEEP is not informative about alveolar recruitment in COVID-19 as well. 


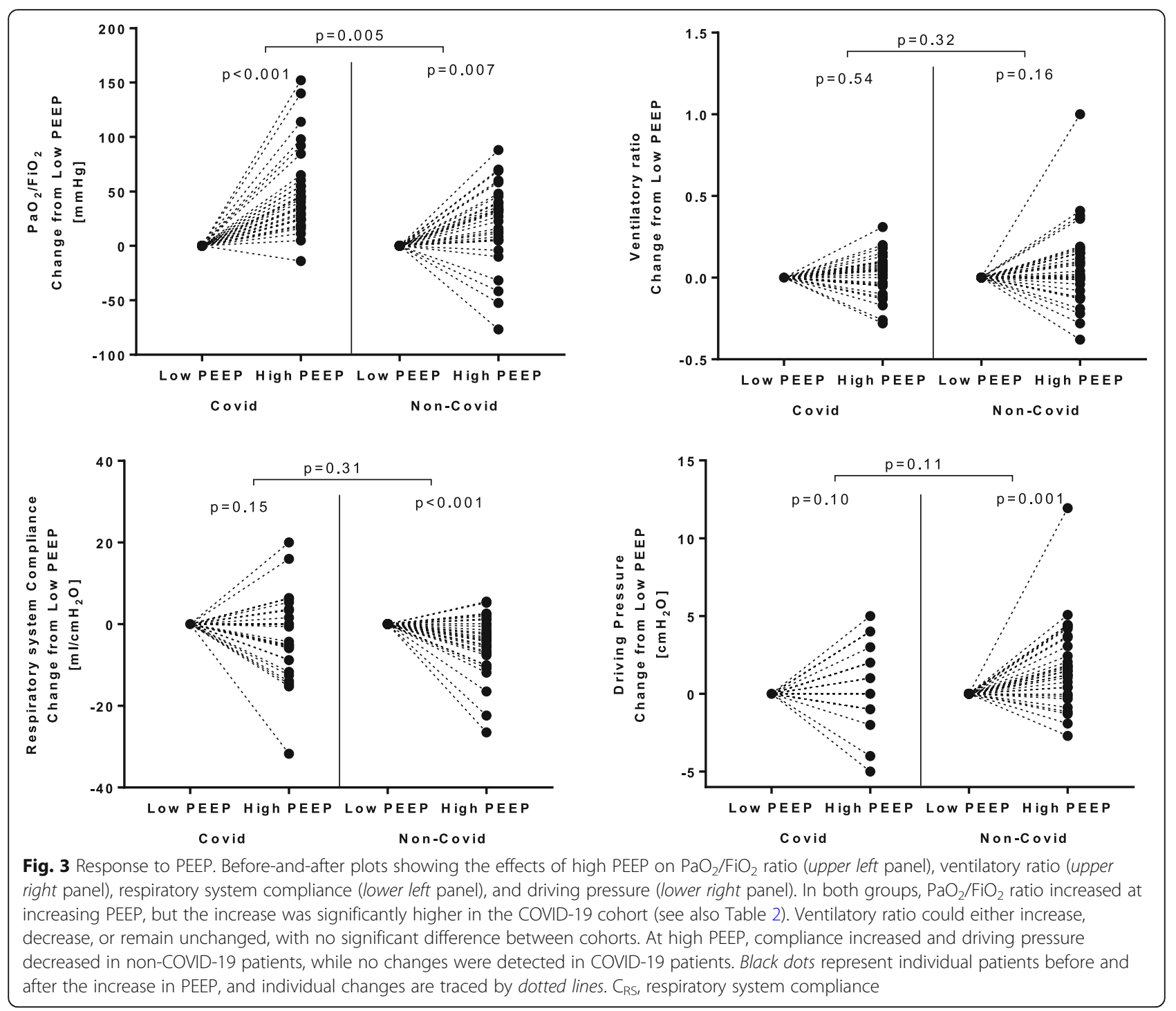

Interestingly, PEEP-induced alveolar recruitment was correlated with $\mathrm{PaCO}_{2}$ changes, and all patients with low potential for lung recruitment developed increases in $\mathrm{PaCO}_{2}$ with high PEEP. Changes in $\mathrm{PaCO}_{2}$ due to PEEP reflect dead space modifications. In case of poorly recruitable lungs, alveolar dead space increases due to compression of pulmonary vessels [48], and airway dead space augments due to gas compression in the respiratory circuit and airways [32]. With alveolar recruitment, overdistension by tidal volume is mitigated, and this reduces ventilation-perfusion mismatch $[49,50]$.

\section{Response to PEEP_recruitability}

In our study, recruitability of COVID-19 patients was variable, with an average value similar to ARDS from other etiologies. Our results are consistent with most recent data indicating great heterogeneity in the response to PEEP in COVID-19 patients [19, 22, 23]. This has relevant clinical implications, as PEEP setting should balance between its capability to recruit new alveoli and the unavoidable overdistension in already open tissue [51, 52]. As such, a high PEEP should be beneficial only in patients having greater potential for lung recruitment, in whom PEEP increases the size of the aerated lung available for tidal ventilation. Conversely, in non-recruitable patients, PEEP only enhances lung injury by increased static stress and strain [50]. Recruitability could not be predicted by changes in oxygenation, compliance, or driving pressure in response to PEEP, which represent popular proposed PEEP-setting strategies [53]. This suggests that bedside assessment of the potential for lung recruitment appears warranted in COVID-19 patients. The recently developed recruitment-to-inflation ratio (which represents recruited volume normalized to 


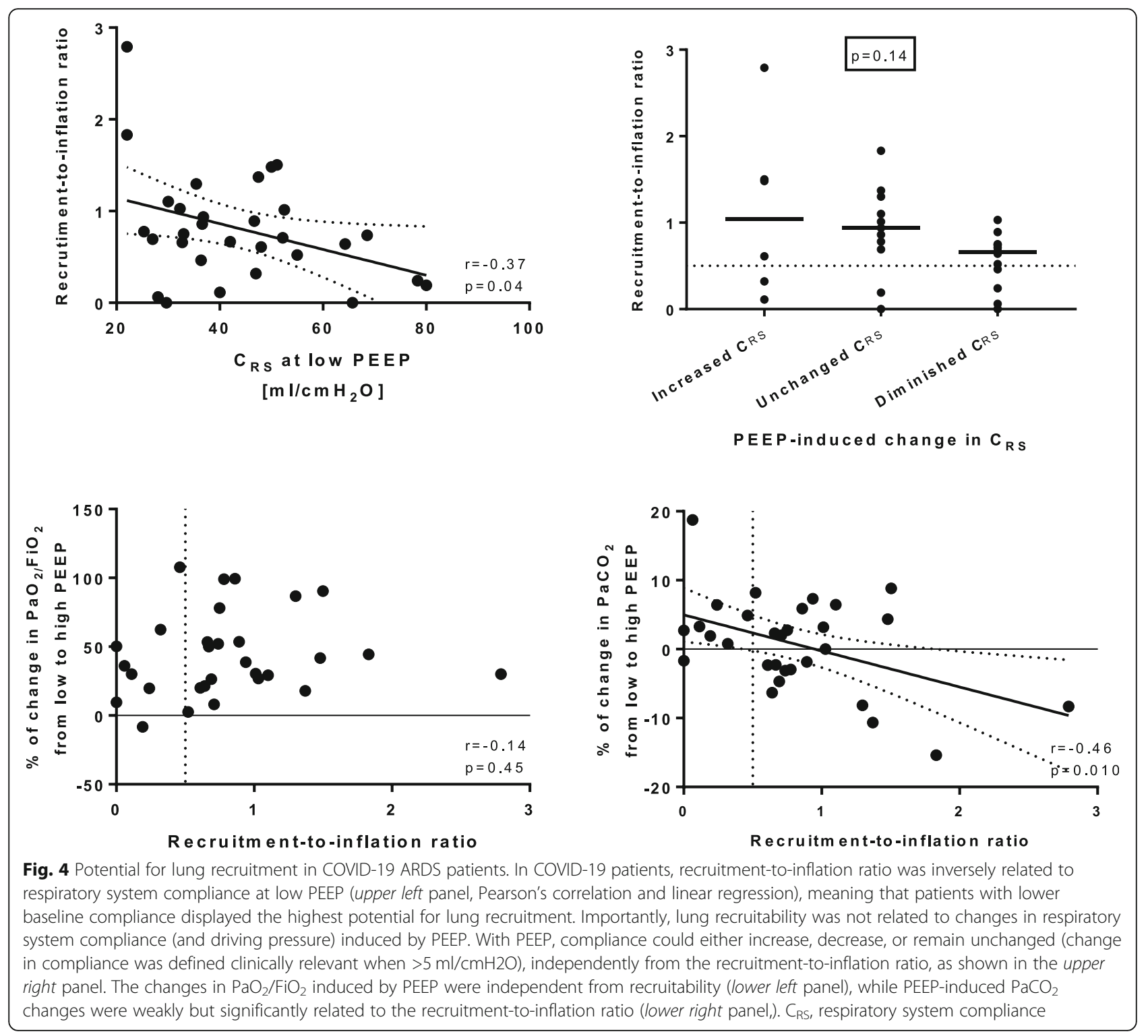

aerated lung size) offers a simple, timely, and reproducible assessment of gas recruitment [29]. This may help distinguish patients showing high vs. low recruitability at the bedside, possibly supporting PEEP setting.

\section{Clinical outcome}

In our study, 28-day mortality of COVID-19 patients was higher than that reported for ARDS of other causes in a large multicenter observational study (35\% for moderate and $43 \%$ for severe ARDS) [14]. We report high mortality rate despite tidal volume, plateau, and driving pressure were within a relatively safe range and prone position was applied in most of the patients. The majority of our patients were intubated after receiving noninvasive respiratory support, which could have selected the most severe population at higher risk for mortality [14, 54-56]. However, the small size of our cohort precludes from further speculation on the reasons for this high mortality.

\section{Limitations}

This study has limitations.

First, our COVID-19 patients were studied within $24 \mathrm{~h}$ after endotracheal intubation: it is possible that respiratory physiology varies over time, as suggested by other investigator showing low respiratory system compliance and minimal recruitability at a later stage of COVID-19 ARDS [57]. This reinforces the clinical message of our 
study, which addresses individualized interventions based on bedside assessment of physiology.

Second, while the matched comparison with nonCOVID-19 historical cohort has several strengths, we cannot exclude that uncontrolled individual characteristics of studied patients affected some of study results. In particular, duration of intubation prior to measurements could not be matched, and patients in the control group showed heterogeneous causes of ARDS: both these features may have affected study results.

\section{Conclusion}

Early after establishment of mechanical ventilation, patients with COVID-19 show a conventional ARDS phenotype, with heterogeneity in respiratory mechanics, aeration loss related to the degree of hypoxemia, and inter-individually variable recruitability. Physiological differences between COVID-19 patients and ARDS from other etiologies appear clinically negligible. Until other data emerge, clinicians treating COVID-19 patients should adhere to most recent guidelines regarding ARDS management.

\section{Supplementary information}

Supplementary information accompanies this paper at https://doi.org/10. 1186/s13054-020-03253-2.

Additional file 1 : Supplementary Table 1. Individual data of studied patients.

\section{Abbreviations}

ARDS: Acute respiratory distress syndrome; PEEP: Positive end-expiratory pressure; BMI: Body mass index; ICU: Intensive care unit

\section{Acknowledgements}

The authors are grateful to all ICU doctors, residents, and nurses whose efforts, devotion to patients, and passion have made possible this timely report.

\section{Authors' contributions}

DLG, FB, LC, LB, and MA conceived the study. DLG, SLC, GP, EST, SC, TM, FT, GMA, GL, GDP, and GB conducted the study on enrolled patients with COVID-induced ARDS. LC and LB provided the data on patients with ARDS from other etiologies. AMDA, DLG, and LC analyzed the data. DLG, FB, and LSM interpreted the data and wrote the first draft of the manuscript. SMM, $L B$, and MA critically revised the manuscript. MA organized the study as an overall supervisor. All the authors reviewed the final draft of the manuscript and agreed on submitting it to the Critical Care.

\section{Funding}

This study was funded solely by institutional/departmental resources. Outside of the submitted work, DLG is supported by grants from SIAARTI and ESICM.

\section{Availability of data and materials}

The datasets used and/or analyzed during the current study are available from the corresponding author on reasonable request.

\section{Ethics approval and consent to participate}

The study was approved by local Ethics Committee, and informed consent was obtained by enrolled patients according to committee recommendation.

\section{Consent for publication}

Not applicable

\section{Competing interests}

DLG has received payments for travel expenses by Maquet, Getinge, and Air Liquide. LB's laboratory has received support for research by Covidien (PAV), Air Liquide (CPR), Philips (equipment for sleep), Fisher \& Paykel (high flow therapy), and GE Healthcare. MA has received personal fees from Maquet and a research grant by Toray. DLG and MA disclose a research grant by General Electric Healthcare.

\section{Author details}

${ }^{1}$ Department of Emergency, Intensive Care Medicine and Anesthesia, Fondazione Policlinico Universitario A. Gemelli IRCCS, Rome, Italy. ${ }^{2}$ Istituto di Anestesiologia e Rianimazione, Università Cattolica del Sacro Cuore, Rome, Italy. ${ }^{3}$ Keenan Centre for Biomedical Research, Li Ka Shing Knowledge Institute, St. Michael's Hospital, Toronto, Canada. ${ }^{4}$ Interdepartmental Division of Critical Care Medicine, University of Toronto, Toronto, Canada.

${ }^{5}$ Department of Basic Biotechnological Science, Università Cattolica del Sacro Cuore, Rome, Italy. ${ }^{6}$ Department of Laboratory and Infectious Diseases, Fondazione Policlinico Universitario A. Gemelli IRCCS, Rome, Italy. ${ }^{7}$ Department of Medical, Oral and Biotechnological Sciences, School of Medicine and Health Sciences, Section of Anesthesia, Analgesia, Perioperative and Intensive Care, SS. Annunziata Hospital, Gabriele d'Annunzio University of Chieti-Pescara, Chieti, Italy.

Received: 12 June 2020 Accepted: 17 August 2020

Published online: 28 August 2020

References

1. Guan W, Ni Z, Hu Y, Liang W-H, Ou C, He J, et al. Clinical Characteristics of Coronavirus Disease 2019 in China. N Engl J Med. 2020;382:1708-20.

2. Wu Z, McGoogan JM. Characteristics of and important lessons from the coronavirus disease 2019 (COVID-19) outbreak in China: summary of a report of 72314 cases from the Chinese Center for Disease Control and Prevention. JAMA. 2020.

3. Del Rio C, Malani PN. COVID-19-new insights on a rapidly changing epidemic. JAMA. 2020.

4. Grasselli G, Zangrillo A, Zanella A, Antonelli M, Cabrini L, Castelli A, et al. Baseline characteristics and outcomes of 1591 patients infected with SARSCoV-2 admitted to ICUs of the Lombardy region. Italy JAMA. 2020;24:122.

5. Cao J, Hu X, Cheng W, Yu L, Tu W-J, Liu Q. Clinical features and short-term outcomes of 18 patients with corona virus disease 2019 in intensive care unit. Intensive Care Med. 2020;46:851-3.

6. Murthy S, Gomersall CD, Fowler RA. Care for critically ill patients with COVID-19. JAMA. 2020.

7. Yang X, Yu Y, Xu J, Shu H, Xia J, Liu H, et al. Clinical course and outcomes of critically ill patients with SARS-CoV-2 pneumonia in Wuhan, China: a singlecentered, retrospective, observational study. Lancet Respir Med. 2020;2600: $1-7$.

8. Richardson S, Hirsch JS, Narasimhan M, Crawford JM, McGinn T, Davidson KW, et al. Presenting characteristics, comorbidities, and outcomes among 5700 patients hospitalized with COVID-19 in the New York City area. JAMA. 2020;10022:1-8,

9. Arentz M, Yim E, Klaff L, Lokhandwala S, Riedo FX, Chong M, et al. Characteristics and outcomes of 21 critically ill patients with COVID-19 in Washington State. JAMA. 2020.

10. Slutsky AS, Ranieri VM. Ventilator-induced lung injury. N Engl J Med. 2013; 369:2126-36.

11. Laffey JG, Bellani G, Pham T, Fan E, Madotto F, Bajwa EK, et al. Potentially modifiable factors contributing to outcome from acute respiratory distress syndrome: the LUNG SAFE study. Intensive Care Med. 2016;42:1865-76.

12. Henderson WR, Chen L, Amato MBP, Brochard LJ. Fifty years of research in ARDS. Respiratory mechanics in acute respiratory distress syndrome. Am J Respir Crit Care Med. 2017;196:822-33.

13. Amato MBP, Meade MO, Slutsky AS, Brochard L, Costa ELV, Schoenfeld DA, et al. Driving pressure and survival in the acute respiratory distress syndrome. N Engl J Med. 2015;372:747-55.

14. Bellani G, Laffey JG, Pham T, Fan E, Brochard L, Esteban A, et al. Epidemiology, patterns of care, and mortality for patients with acute respiratory distress syndrome in intensive care units in 50 countries. JAMA. 2016;315:788-800.

15. Goligher EC, Dres M, Patel BK, Sahetya SK, Beitler JR, Telias I, et al. Lung and diaphragm-protective ventilation. Am J Respir Crit Care Med. 2020. 
16. Tobin MJ. Basing respiratory management of coronavirus on physiological principles. Am J Respir Crit Care Med. 2020;60141:1-9.

17. Marini JJ, Gattinoni L. Management of COVID-19 respiratory distress. JAMA. 2020.

18. Gattinoni L, Chiumello D, Caironi P, Busana M, Romitti F, Brazzi L, et al. COVID-19 pneumonia: different respiratory treatments for different phenotypes? Intensive Care Med. 2020;46:1099-102.

19. Haudebourg A-F, Perier F, Tuffet $S$, de Prost N, Razazi K, Mekontso Dessap A, et al. Respiratory mechanics of COVID-19- versus non-COVID-19-associated acute respiratory distress syndrome. Am J Respir Crit Care Med. 2020;202: 287-90.

20. Pan C, Chen L, Lu C, Zhang W, Xia J-AA, Sklar MC, et al. Lung Recruitability in SARS-CoV-2 Associated Acute Respiratory Distress Syndrome: A Singlecenter, Observational Study. Am J Respir Crit Care Med. 2020;201:1294-7.

21. Liu X, Liu X, Xu Y, Xu Z, Huang Y, Chen S, et al. Ventilatory Ratio in Hypercapnic Mechanically Ventilated Patients with COVID-19-associated Acute Respiratory Distress Syndrome. Am J Respir Crit Care Med. 2020;201: 1297-9.

22. Mauri T, Spinelli E, Scotti E, Colussi G, Basile MC, Crotti S, et al. Potential for lung recruitment and ventilation-perfusion mismatch in patients with the acute respiratory distress syndrome from coronavirus disease. Crit Care Med. 2019;2020:1-6.

23. Beloncle FM, Pavlovsky B, Desprez C, Fage N, Olivier P-Y, Asfar P, et al. Recruitability and effect of PEEP in SARS-Cov-2-associated acute respiratory distress syndrome. Ann Intensive Care. 2020;10:55.

24. Definition Task Force ARDS, Ranieri VM, Rubenfeld GD, Thompson BT, Ferguson ND, Caldwell E, et al. Acute respiratory distress syndrome: the Berlin Definition. JAMA. 2012;307:2526-33.

25. Caironi $\mathrm{P}$, Carlesso E, Cressoni M, Chiumello D, Moerer O, Chiurazzi C, et al. Lung recruitability is better estimated according to the Berlin definition of acute respiratory distress syndrome at standard $5 \mathrm{~cm} \mathrm{H} 2 \mathrm{O}$ rather than higher positive end-expiratory pressure. Crit Care Med. 2015;43:781-90.

26. Papazian L, Forel J-M, Gacouin A, Penot-Ragon C, Perrin G, Loundou A, et al. Neuromuscular blockers in early acute respiratory distress syndrome. N Engl J Med. 2010;363:1107-16.

27. Sinha P, Calfee CS, Beitler JR, Soni N, Ho K, Matthay MA, et al. Physiologic analysis and clinical performance of the ventilatory ratio in acute respiratory distress syndrome. Am J Respir Crit Care Med. 2019;199:333-41.

28. Chen L, Chen G-Q, Shore K, Shklar O, Martins C, Devenyi B, et al. Implementing a bedside assessment of respiratory mechanics in patients with acute respiratory distress syndrome. Crit Care. 2017;21:84.

29. Chen L, Del Sorbo L, Grieco DL, Junhasavasdikul D, Rittayamai N, Soliman I, et al. Potential for lung recruitment estimated by the recruitment-toinflation ratio in acute respiratory distress syndrome. A clinical trial. Am J Respir Crit Care Med. 2020;201:178-87.

30. Yonis H, Mortaza S, Baboi L, Mercat A, Guérin C. Expiratory flow limitation assessment in patients with acute respiratory distress syndrome. A reappraisal. Am J Respir Crit Care Med. 2018;198:131-4.

31. Grieco DL, Anzellotti GM, Russo A, Bongiovanni F, Costantini B, D'Indinosante $M$, et al. Airway closure during surgical pneumoperitoneum in obese patients. Anesthesiology. 2019;131:58-73.

32. Chen L, Del Sorbo L, Grieco DL, Shklar O, Junhasavasdikul D, Telias I, et al. Airway closure in acute respiratory distress syndrome: an underestimated and misinterpreted phenomenon. Am J Respir Crit Care Med. 2018;197:132-6.

33. Volta CA, Dalla Corte F, Ragazzi R, Marangoni E, Fogagnolo A, Scaramuzzo $G$, et al. Expiratory flow limitation in intensive care: prevalence and risk factors. Crit Care. 2019;23:395.

34. Gattinoni L, Coppola S, Cressoni M, Busana M, Rossi S, Chiumello D. COVID19 Does Not Lead to a "Typical" Acute Respiratory Distress Syndrome. Am J Respir Crit Care Med. 2020;201:1299-300.

35. Gattinoni L, Pesenti A, Avalli L, Rossi F, Bombino M. Pressure-volume curve of total respiratory system in acute respiratory failure. Computed tomographic scan study. Am Rev Respir Dis. 1987;136:730-6.

36. Grieco DL, Russo A, Romanò B, Anzellotti GM, Ciocchetti P, Torrini F, et al. Lung volumes, respiratory mechanics and dynamic strain during general anaesthesia. Br J Anaesth. 2018;121:1156-65.

37. Gattinoni L, Marini JJ, Pesenti A, Quintel M, Mancebo J, Brochard L. The "baby lung" became an adult. Intensive Care Med. 2016;42:663-73.

38. Gattinoni L, Pesenti A. The concept of "baby lung". Intensive Care Med. 2005:31:776-84.
39. Ferrando C, Suarez-Sipmann F, Mellado-Artigas R, Hernández M, Gea A, Arruti E, et al. Clinical features, ventilatory management, and outcome of ARDS caused by COVID-19 are similar to other causes of ARDS. Intensive Care Med. 2020.

40. Laverdure F, Delaporte A, Bouteau A, Genty T, Decailliot F, Stéphan F. Impact of initial respiratory compliance in ventilated patients with acute respiratory distress syndrome related to COVID-19. Crit Care. 2020;24:412.

41. Diehl J-L, Peron N, Chocron R, Debuc B, Guerot E, Hauw-Berlemont C, et al. Respiratory mechanics and gas exchanges in the early course of COVID-19 ARDS: a hypothesis-generating study. Ann Intensive Care. 2020;10:95.

42. Fan E, Beitler JR, Brochard L, Calfee CS, Ferguson ND, Slutsky AS, et al. COVID-19-associated acute respiratory distress syndrome: is a different approach to management warranted? Lancet Respir Med. 2020;2600:1-6.

43. Spinelli E, Grieco DL, Mauri T. A personalized approach to the acute respiratory distress syndrome: recent advances and future challenges. J Thorac Dis. 2019;11:5619-25.

44. Fan E, Del Sorbo L, Goligher EC, Hodgson CL, Munshi L, Walkey AJ, et al. An official American Thoracic Society/European Society of Intensive Care Medicine/Society of Critical Care Medicine clinical practice guideline: mechanical ventilation in adult patients with acute respiratory distress syndrome. Am J Respir Crit Care Med. 2017;195:1253-63.

45. Santamarina MG, Boisier D, Contreras R, Baque M, Volpacchio M, Beddings I. COVID-19: a hypothesis regarding the ventilation-perfusion mismatch. Crit Care. 2020;24:395

46. Tomashefski JF, Davies P, Boggis C, Greene R, Zapol WM, Reid LM. The pulmonary vascular lesions of the adult respiratory distress syndrome. Am J Pathol. 1983;112:112-26.

47. Leisman DE, Deutschman CS, Legrand M. Facing COVID-19 in the ICU: vascular dysfunction, thrombosis, and dysregulated inflammation. Intensive Care Med. 2020;46:1105-8.

48. Pintado M-C, de Pablo R, Trascasa M, Milicua J-M, Rogero S, Daguerre M, et al. Individualized PEEP setting in subjects with ARDS: a randomized controlled pilot study. Respir Care. 2013;58:1416-23.

49. Eronia N, Mauri T, Maffezzini E, Gatti S, Bronco A, Alban L, et al. Bedside selection of positive end-expiratory pressure by electrical impedance tomography in hypoxemic patients: a feasibility study. Ann Intensive Care. 2017;7:76

50. Bellani G, Guerra L, Musch G, Zanella A, Patroniti N, Mauri T, et al. Lung regional metabolic activity and gas volume changes induced by tidal ventilation in patients with acute lung injury. Am J Respir Crit Care Med. 2011;183:1193-9.

51. Chiumello D, Carlesso E, Cadringher P, Caironi P, Valenza F, Polli F, et al. Lung stress and strain during mechanical ventilation for acute respiratory distress syndrome. Am J Respir Crit Care Med. 2008;178:346-55.

52. Protti A, Andreis DT, Monti M, Santini A, Sparacino CC, Langer T, et al. Lung stress and strain during mechanical ventilation: any difference between statics and dynamics? Crit Care Med. 2013;41:1046-55.

53. Writing Group for the Alveolar Recruitment for Acute Respiratory Distress Syndrome Trial (ART) Investigators, Cavalcanti AB, Suzumura ÉA, Laranjeira $L N$, de Paisani DM, Damiani LP, et al. Effect of lung recruitment and titrated positive end-expiratory pressure (PEEP) vs low PEEP on mortality in patients with acute respiratory distress syndrome: a randomized clinical trial. JAMA. 2017;318:1335-45.

54. Grieco DL, Menga LS, Raggi V, Bongiovanni F, Anzellotti GM, Tanzarella ES, et al. Physiological comparison of high-flow nasal cannula and helmet noninvasive ventilation in acute hypoxemic respiratory failure. Am J Respir Crit Care Med. 2020;201:303-12.

55. Grieco DL, Menga LS, Eleuteri D, Antonelli M. Patient self-inflicted lung injury: implications for acute hypoxemic respiratory failure and ARDS patients on non-invasive support. Minerva Anestesiol. 2019;85:1014-23.

56. Bellani G, Laffey JG, Pham T, Madotto F, Fan E, Brochard L, et al. Noninvasive ventilation of patients with acute respiratory distress syndrome. Insights from the LUNG SAFE study. Am J Respir Crit Care Med. 2017;195:67-77.

57. Pan C, Chen L, Lu C, Zhang W, Xia JA, Sklar MC, et al. Lung recruitability in COVID-19-associated acute respiratory distress syndrome: a single-center observational study. Am J Respir Crit Care Med. 2020;201:1294-7.

\section{Publisher's Note}

Springer Nature remains neutral with regard to jurisdictional claims in published maps and institutional affiliations. 